\title{
Tandem chemoselective Suzuki-Miyaura cross-coupling enabled by nucleophile speciation control
}

\author{
Ciaran. P. Seath, James W. B. Fyfe, John J. Molloy and Allan J. B. Watson*
}

\begin{abstract}
Control of boronic acid speciation is presented as a strategy to achieve nucleophile chemoselectivity in the SuzukiMiyaura reaction. Combined with simultaneous control of oxidative addition and transmetallation, this enables chemoselective formation of two C-C bonds in a single operation, providing a method for the rapid preparation of highly functionalized carbogenic frameworks.
\end{abstract}

The Suzuki-Miyaura reaction is the primary method for Pdcatalyzed cross-coupling, accounting for over $40 \%$ of C-C bond constructions in the pharmaceutical industry alone.$^{[1,2]}$ Chemoselective control of this reaction is currently limited to single mechanistic events, focusing on either the electrophile or nucleophile independently. ${ }^{[3]}$ Electrophile selectivity has been thoroughly demonstrated by exploiting the well-defined principles of oxidative addition $(\mathrm{I}>\mathrm{Br}>\mathrm{Cl} \text {, etc.; Scheme } 1 \mathrm{a})^{[4,5]}$ while nucleophile selectivity has been achieved through the use of inert (protected) boronic acid derivatives (Scheme $1 \mathrm{~b}(\mathrm{i}))^{[6]}$ or a geminal/vicinal diboron self-activation mechanism (Scheme 1b (ii)) ${ }^{[7]}$ Despite these advances, general nucleophile chemoselectivity remains elusive. Reactions are therefore limited to only one selective C-C bond forming event, ${ }^{[8]}$ with sequential chemoselective cross-coupling achieved only through separate reactions ${ }^{[3,6 n, 9]}$ Establishing simultaneous electrophile and nucleophile selectivity to allow successive C-C bondforming events in a single reaction remains unsolved.

a) Previous work: chemoselective oxidative addition (OA)
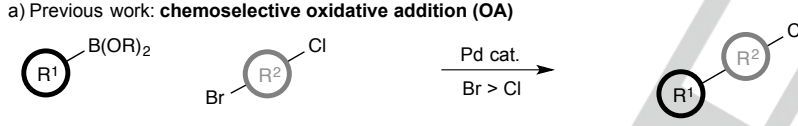

b) Previous work: chemoselective transmetallation (TM) (i) Protected boronic acids
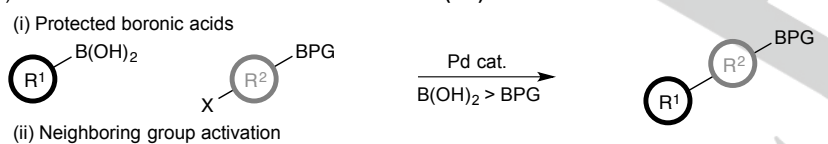
$\mathrm{BPin}^{2}$
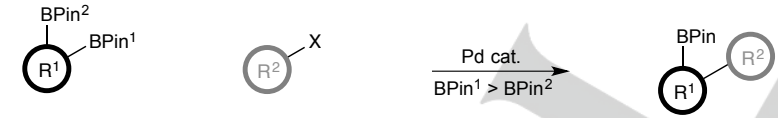

c) This work: tandem Suzuki-Miyaura cross-coupling via complete chemoselective control

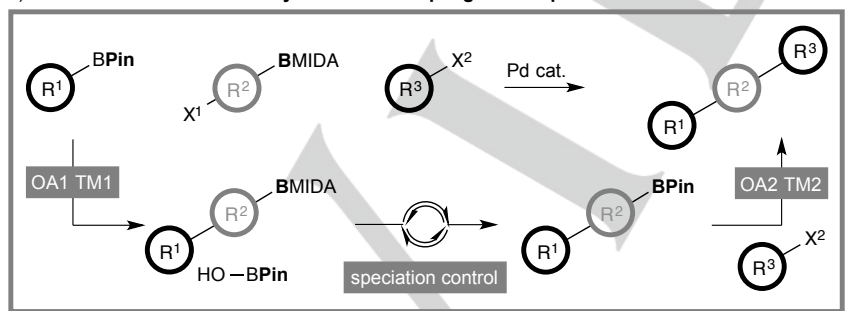

Scheme 1. Approaches to chemoselective Suzuki-Miyaura cross-coupling Cat=catalyst, $\quad \mathrm{MIDA}=\mathrm{N}$-methyliminodiacetic acid, $\mathrm{OA}=$ oxidative addition, $\mathrm{PG}=$ protecting group, $\mathrm{Pin}=$ pinacolato, $\mathrm{TM}=$ transmetallation.

C. P. Seath, J. W. B. Fyfe, J. J. Molloy, Dr. A. J. B. Watson

WestCHEM, Department of Pure and Applied Chemistry

University of Strathclyde

295 Cathedral Street, Glasgow, G1 1XL (UK)

E-mail: allan.watson.100@strath.ac.uk

Supporting information for this article is given via a link at the end of the document.
Recently, we demonstrated that boron speciation can be controlled during Suzuki-Miyaura cross-coupling to enable chemoselective and quantitative ligand exchange in situ. ${ }^{[10]}$ Here we report that boron speciation, oxidative addition, and transmetallation can be simultaneously controlled to enable two chemoselective Suzuki-Miyaura C-C bond formations in a single catalytic process (Scheme 1c). This provides a simple yet powerful solution to achieving nucleophile chemoselectivity and enables the rapid and efficient synthesis of high value products.

Tandem chemoselective Suzuki-Miyaura cross-coupling was initially explored using the benchmark reaction of phenyl BPin 1, 4-bromophenyl BMIDA 2, and aryl chloride 3 (Table 1). The reaction design plan required three distinct chemoselective events to cooperate simultaneously. Cross-coupling of 1 and 2 to produce the expected biaryl BMIDA intermediate $4{ }^{[6 r, 10]}$ based upon selective oxidative addition of $\mathbf{2}$ vs. 3 and transmetallation of 1 vs. 2; (ii) formation of BPin 6 from the BMIDA intermediate and 5 via control of speciation; ${ }^{[10]}$ and (iii) cross-coupling of 6 with 3 to deliver $7 a$. Control of these events represented a significant challenge. Chemoselective oxidative addition can be capricious and reaction/catalyst dependent ${ }^{[4 a, 5]}$ - premature reaction of $\mathbf{1}$ and $\mathbf{3}$ would deliver $\mathbf{8}$. Hydrolysis of $\mathbf{2}$ must be controlled to avoid premature transmetallation of the latent boronic acid and uncontrolled oligomerization, leading to $\mathbf{9} .^{[10,11]}$ However, this must be levied against the requirement of aqueous base to facilitate effective cross-coupling ${ }^{[12]}$ and ensure effective speciation manipulation. ${ }^{[10]}$

Table 1. Reaction development.

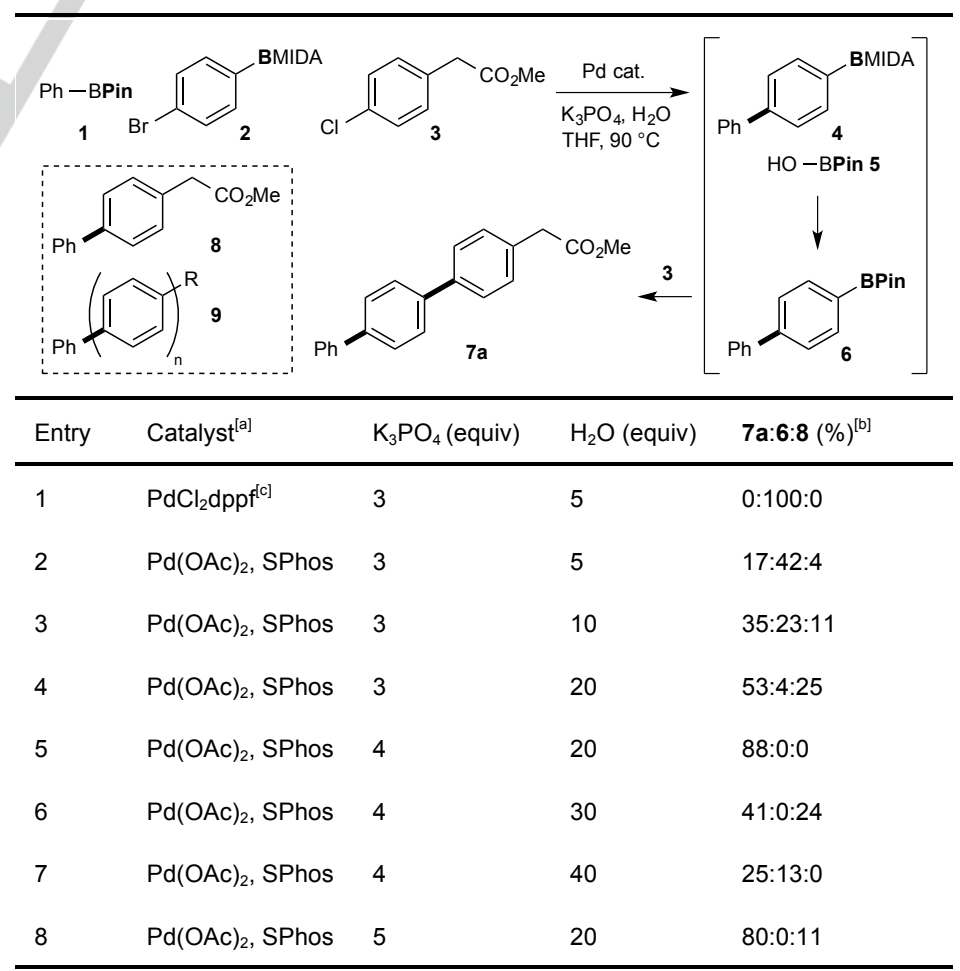

[a] 4 mol\% Pd, 8 mol\% ligand. [b] Determined by HPLC analysis. [c] 4 mol\%. 
Initial evaluation of a catalyst system based on our previous work failed to deliver the desired triaryl product $7 \mathrm{a}$; the reaction produced only the formal homologation adduct 6 with aryl chloride 3 returned, indicating problematic oxidative addition with this less reactive electrophile (entry 1). Moving to a more activated catalyst system $\left(\mathrm{Pd}(\mathrm{OAc})_{2}\right.$, SPhos; ${ }^{[13,14]}$ entry 2) provided low conversion to $7 \mathrm{a}$ with the mass balance consisting mainly of $\mathbf{6}$ as well as $\mathbf{8}$, the product of reaction of $\mathbf{1}+\mathbf{3}$, indicating a lack of electrophile chemoselectivity. Lowering the reaction temperature to avoid premature engagement of $\mathbf{3}$ led to lower overall conversion (see $\mathrm{ESI}$ ). A systematic evaluation of the stoichiometric relationship between $\mathrm{K}_{3} \mathrm{PO}_{4}$ (a range of bases were evaluated, see ESI) and $\mathrm{H}_{2} \mathrm{O}$ revealed that cross-coupling efficiency could be directly influenced by the medium without resorting to specific tailoring of the catalyst. ${ }^{[5]}$ Increasing the quantity of $\mathrm{H}_{2} \mathrm{O}$ increased the overall conversion (i.e., improved engagement of 3 ) but also led to extensive oligomerization due to poor speciation control (entries 3 and 4). This could be mitigated by increasing the quantity of $\mathrm{K}_{3} \mathrm{PO}_{4},{ }^{[10]}$ which provided excellent levels of conversion to $7 \mathrm{a}$ (entry 5 ). Further increases in $\mathrm{H}_{2} \mathrm{O}$ led to oligomerization giving increased 9 (entries 6 and 7), which could again be tempered by increasing the quantity of $\mathrm{K}_{3} \mathrm{PO}_{4}$ (entry 8). Accordingly, these results further demonstrate that in addition to speciation control, cross-coupling efficiency can also be directly influenced by relatively minor adjustments to the composition of the reaction medium. ${ }^{[1 c]}$ A survey of various catalyst systems with the optimum biphase composition did not provide any further improvement in the chemical yield (see ESI).

It is important to note that the optimized reaction is effective with equal stoichiometries of 1,2 , and 3 , i.e., the chemoselectivity and yield are not statistically prejudiced through use of impractical and uneconomical stoichiometries of any component or by tailoring (e.g., electronic or steric bias) of the nucleophile. ${ }^{[9]}$ The reaction rates are harmonized such that BPin 1 reacts only with aryl bromide 2, speciation control delivers BPin 6 at a rate that avoids oligomerization or competition with $1,{ }^{[10 \mathrm{~b}]}$ and 6 reacts only with aryl chloride 3 .

With our optimum reaction conditions in hand, the scope of the tandem cross-coupling protocol was explored (Scheme 2). The general concept was also readily transferred to a modified system using dihaloarenes as conjunctive bis-electrophiles in combination with two differentiated boronic acid-derived nucleophiles (Scheme 3 ). In this process, the slightly less active DavePhos $^{[14,15]}$ ligand was found to be more suitable. The reaction efficiencies between the two complementary processes are comparable, for example, the preparation of $7 \mathbf{a}$ is produced in $82 \%$ and $91 \%$ yield, respectively (Scheme 2 vs. Scheme 3). This synthetic flexibility provides an array of diverse product scaffolds in a single operation and enhances scope based on the wider selection of available reaction components.

A broad range of coupling partner was accommodated in both protocols, including useful functionality on the BPin, BMIDA, and aryl chloride components, such as ethers, esters, fluorides, nitriles, ketones, olefins, and heterocyclic residues. Notably, heteroaryl and alkenyl BMIDA, which must progress via the protodeboronation prone parent boronic acids, ${ }^{[6 e, 16]}$ were effectively incorporated. Yields were typically high and synthetically useful, especially when the number of individual processes is considered.

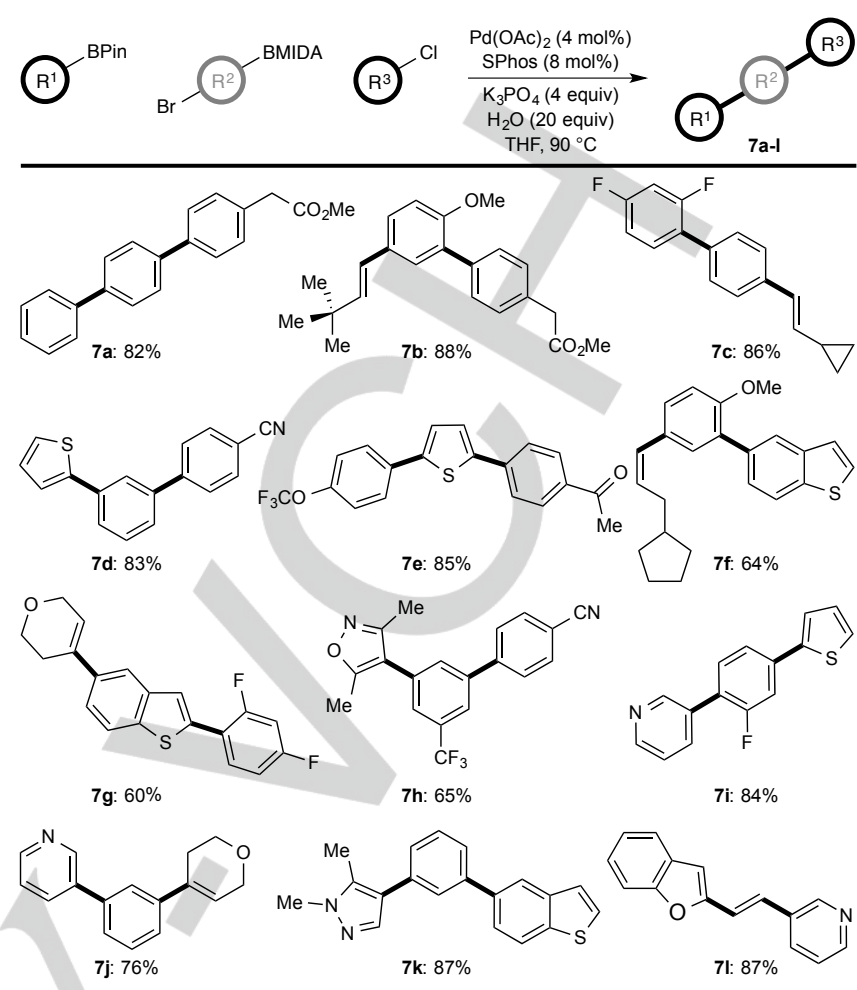

Scheme 2. Chemoselective tandem Suzuki-Miyaura cross-coupling using conjunctive haloaryl BMIDA components. Isolated yields of pure products.
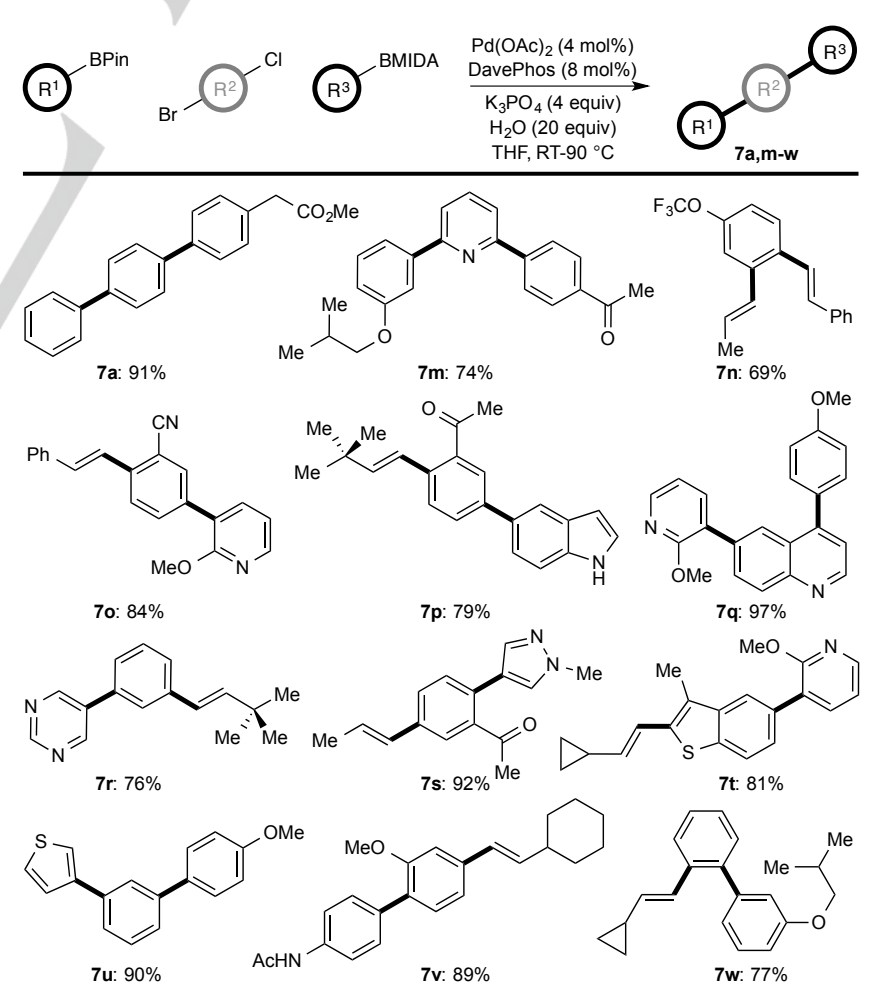

Scheme 3. Chemoselective tandem Suzuki-Miyaura cross-coupling using conjunctive dihalide components. Isolated yields of pure products. Ac=acetyl. 
In a departure from exploiting the standard reactivity profiles of the electrophile (i.e., $\mathrm{Br}>\mathrm{Cl}$ ), we sought to further demonstrate the potential of tandem chemoselective SuzukiMiyaura cross-coupling by utilizing specific reactivity gradients of dibromo- or dichloro-electrophiles (Scheme 4). For example, tandem C-C bond formation was possible using 2,4dichloropyrimidine to deliver $8 \mathbf{a}$ in $70 \%$ yield. ${ }^{[17]}$ The increased lability of alkenyl electrophiles vs. aryl electrophiles allows chemoselective cross coupling of $1, \beta$-dibromostyrene to provide $\mathbf{8 b}$ in $79 \%$ yield. ${ }^{[18]}$ Similarly, $\mathrm{sp}^{2} / \mathrm{sp}^{3}$ electrophile selectivity can be achieved using 4-bromobenzyl bromide to provide $8 \mathrm{c}$ in $84 \%$ yield. Lastly, more subtle effects can be exploited: Dihaloarenes have been shown to undergo either selective mono-arylation or exhaustive arylation under specific Suzuki-Miyaura conditions. ${ }^{[8,19]}$ Under our developed protocol, 1,4dibromobenzene undergoes sequential chemoselective $\mathrm{C}-\mathrm{C}$ bond formation to provide $8 \mathrm{~d}$ in $60 \%$ yield.

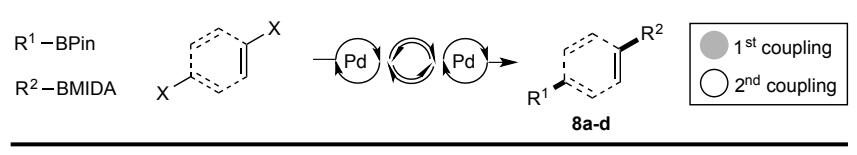<smiles>[Li]c1ccnc(-c2ccccc2)n1</smiles><smiles>Brc1ccc(CC2CCCC2)cc1</smiles><smiles>[13CH2]c1ccc(Br)cc1</smiles>
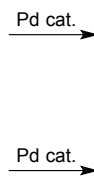

$\stackrel{\text { Pd cat. }}{\longrightarrow}$
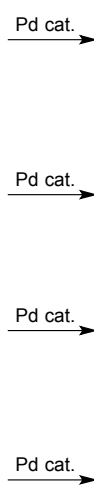<smiles>BrC=Cc1ccc(Br)cc1</smiles>

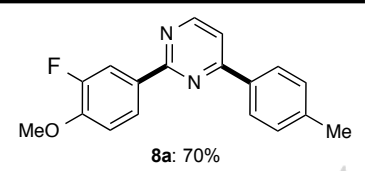

8a: $70 \%$<smiles>[AlH2]</smiles>

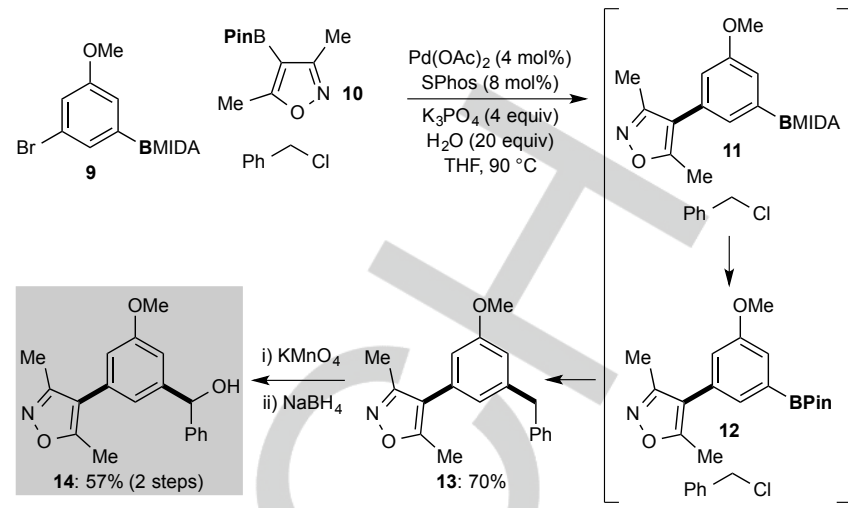

Scheme 5. Synthesis of BET bromodomain inhibitor 14 via tandem $\mathrm{sp}^{2}$ $\mathrm{sp}^{2} / \mathrm{sp}^{2}-\mathrm{sp}^{3}$ Suzuki-Miyaura cross-coupling.

\section{Acknowledgements}

We thank the Carnegie Trust for a PhD Scholarship (CPS), the EPSRC UK National Mass Spectrometry Facility at Swansea University for analyses, and GlaxoSmithKline for chemical resources.

Keywords: boron $\bullet$ chemoselectivity• cross-coupling $\bullet$ palladium - speciation

[1] For selected reviews, see: a) N. Miyaura, A. Suzuki, Chem. Rev. 1995 95, 2457-2483; b) A. J. J. Lennox, G. C. Lloyd-Jones, Angew. Chem. Int. Ed. 2013, 52, 7362-7370; Angew. Chem. 2013, 125, 7506-7515; c) A. J. J. Lennox, G. C. Lloyd-Jones, Chem. Soc. Rev. 2014, 43, 412-443.

[2] S. D. Roughley, A. M. Jordan, J. Med. Chem. 2011, 54, 3451-3479.

[3] For a review, see: J. W. B. Fyfe, A. J. B. Watson, Synlett 2015, 26, 1139-1144

[4] a) A. F. Littke, C. Dai, G. C. Fu, J. Am. Chem. Soc. 2000, 122, 40204028. For a recent example, see: b) A. K. Pitts, F. O'Hara, R. H. Snell, M. J. Gaunt, Angew. Chem. Int. Ed. 2015, 54, 5451-5455; Angew. Chem. 2015, 127, 5541-5545.

[5] For reviews, see: a) Z. Hassan, T. Patonay, P. Langer, Synlett 2013, 24 , 412-423; b) J.-R. Wang, K. Manabe, Synthesis 2009, 1405-1427; c) I. J. S. Fairlamb, Chem. Soc. Rev. 2007, 36, 1036-1045.

Scheme 4. Chemoselective tandem Suzuki-Miyaura cross-coupling using dibromo- and dichloro-electrophiles. Isolated yields of pure products.

The synthetic applicability of our protocol was further exemplified in the rapid synthesis of the BET bromodomain inhibitor 14 (Scheme 5). ${ }^{[20]}$ Chemoselective $\mathrm{sp}^{2}-\mathrm{sp}^{2}$ crosscoupling of conjunctive bromoaryl BMIDA 9 and dimethyl isoxazole BPin 10, delivers intermediate BMIDA 11, which is converted to the reactive BPin derivative 12 in situ via speciation control. This then engages benzyl chloride in an $\mathrm{sp}^{2}-\mathrm{sp}^{3} \mathrm{C}-\mathrm{C}$ bond formation to provide the key core structure 13 in $70 \%$ yield. Oxidation and reduction delivers 14

In conclusion, we have shown that oxidative addition, boron speciation, and transmetallation can be chemoselectively and simultaneously controlled to enable tandem Suzuki-Miyaura C-C bond formation in a single operation. This method provides a simple solution to the nucleophile selectivity issue within SuzukiMiyaura cross-coupling and demonstrates the power of chemoselective cross-coupling to access highly functionalized carbogenic frameworks.
[6] For examples, see: a) L. Xu, P. Li, Chem. Commun. 2015, 51, 56565659; b) J. Li, S. G. Ballmer, E. P. Gillis, S. Fujii, M. J. Schmidt, A. M. E. Palazzolo, J. W. Lehmann, G. F. Morehouse, M. D. Burke, Science 2015, 347, 1221-1226; c) L. Xu, P. Li, Synlett 2014, 25, 1799-1802; d) L. Xu, S. Ding, P. Li, Angew. Chem. Int. Ed. 2014, 53, 1822-1826; Angew. Chem. 2014, 126, 1853-1857; e) E. M. Woerly, J. Roy, M. D. Burke, Nature Chem. 2014, 6, 484-491; f) A. J. Lennox, G. C. LloydJones, J. Am. Chem. Soc. 2012, 134, 7431-7441; g) S. Fujii, S. Y. Chang, M. D. Burke, Angew. Chem. Int. Ed. 2011, 50, 7862-7864; Angew. Chem. 2011, 123, 8008-8010; h) S. J. Lee, T. M. Anderson, M. D. Burke, Angew. Chem. Int. Ed. 2010, 49, 8860-8863; Angew. Chem. 2010, 122, 9044-9047; i) E. M. Woerly, A. H. Cherney, E. K. Davis, M. D. Burke, J. Am. Chem. Soc. 2010, 132, 6941-6943; j) N. Iwadate, M. Suginome, J. Am. Chem. Soc. 2010, 132, 2548-2549; k) N. Iwadate, M. Suginome, Chem. Lett. 2010, 39, 558-560; I) M. Tobisu, N. Chatani, Angew. Chem. Int. Ed., 2009, 48, 3565-3568; Angew. Chem. 2009, 121, 3617-3620; m) N. Iwadate, M. Suginome, Org. Lett. 2009, 11, 1899-1902; n) E. P. Gillis, M. D. Burke, Aldrichimica Acta 2009, 42, 1727; o) G. Molander, D. L. Sandrock, J. Am. Chem. Soc. 2008, 130, 15792-15793; p) S. J. Lee, K. C. Gray, J. S. Paek, M. D. Burke, J. Am. 
Chem. Soc. 2008, 130, 466-468; q) H. Noguchi, T. Shioda, C.-M. Chou, M. Suginome, Org. Lett. 2008, 10, 377-380; r) E. P. Gillis, M. D. Burke J. Am. Chem. Soc. 2007, 129, 6716-6717; s) H. Noguchi, K. Hoj, M. Suginome, J. Am. Chem. Soc. 2007, 129, 758-759.

[7] For examples, see: a) S. N. Mlynarski, C. H. Schuster, J. P. Morken, Nature 2014, 505, 386-390; b) C. Sun, B. Potter, J. P. Morken, J. Am Chem. Soc. 2014, 136, 6534-6537; c) K. Endo, T. Ohkubo, M. Hirokami, T. Shibata, J. Am. Chem. Soc. 2010, 132, 11033-11035. For similar diboron systems using protecting groups, see: e) $\mathrm{X}$. Feng, $\mathrm{H}$. Jeon, J. Yun, Angew. Chem. Int. Ed. 2013, 52, 3989-3992; Angew. Chem. 2013, 125, 4081-4084; f) J. C. H. Lee, R. McDonald, D. G. Hall, Nature Chem. 2011, 3, 894-899.

[8] For examples of exhaustive Suzuki-Miyaura reactions, see: a) C.-G Dong, Q.-S. Hu, J. Am. Chem. Soc. 2005, 127, 10006-10007; b) A Salomone, P. Marilena, I. C. Donato, M. P. Filippo, F. Saverio, C. Vito, Synlett 2011, 1761-1765.

[9] Moderately selective counter-statistical cross-coupling can be achieved with electronically-orthogonal nucleophiles. For example, see: F. Beaumard, P. Dauban, R. H. Dodd, Org. Lett. 2009, 11, 1801-1804.

[10] a) J. W. B. Fyfe, C. P. Seath, A. J. B. Watson, Angew. Chem. Int Ed. 2014, 53, 12077-12080; Angew. Chem. 2014, 126, 12273-12276; b) J. W. B. Fyfe, E. Valverde, C. P. Seath, A. R. Kennedy, N. A Anderson, J. M. Redmond, A. J. B. Watson, Chem.-Eur. J. 2015, 21, 8951-8964. See also: c) J. J. Molloy, R. P. Law, J. W. B. Fyfe, C. P. Seath, D. J. Hirst, A. J. B. Watson, Org. Biomol. Chem., 2015, 13 3093-3102.

[11] For further information relating to oligomerization of haloaryl BMIDA species during Suzuki-Miyaura cross-coupling, see refs $10 \mathrm{a}$ and $10 \mathrm{~b}$.

[12] C. Amatore, A. Jutand, G. Le Duc, Chem. Eur. J. 2011, 17, 2492-2503. See also: C. Amatore, A. Jutand, G. Le Duc, Chem. Eur. J. 2012, 18 6616-6625.
[13] T. E. Barder, S. D. Walker, J. R. Martinelli, J. Am. Chem. Soc. 2005, 127, 4685-4696.

[14] For a review of biaryl phosphine ligands, see: D. S. Surry, S. L. Buchwald, Chem. Sci. 2011, 2, 27-50.

[15] D. W. Old, J. P. Wolfe, S. L. Buchwald, J. Am. Chem. Soc. 1998, 120 , 9722-9723.

[16] G. R. Dick, E. M. Woerly, M. D. Burke, Angew. Chem. Int. Ed. 2012, 51, 2667-2672; Angew. Chem. 2012, 124, 2721-2726.

[17] For a review of chemoselective cross-coupling using dihaloheterocycles, see: S. Schröter, C. Stock, T. Bach, Tetrahedron 2005, 61, 2245-2267.

[18] For examples of alkenyl bromide vs. aryl bromide, see: a) G. Chelucci, Chem. Commun. 2014, 50, 4069-4072; b) K. J. Powell, L.-C. Han, P. Sharma, J. E. Moses, Org. Lett. 2014, 16, 2158-2161; c) D. Kundu, S. Bhadra, N. Mukherjee, B. Sreedhar, B. C. Ranu, Chem.-Eur. J. 2014, 19, 15759-15768; d) J.-P. Wan, C. Wang, Y. Liu, Appl. Organomet. Chem. 2012, 26, 445-447; Y. Liu, J. Yang, W. Bao, Eur. J. Org. Chem. 2009, 31, 5317-5320.

[19] a) D. J. Sinclair, M. S. Sherburn, J. Org. Chem. 2005, 70, 3730-3733. See also: b) C. Minard, C. Palacio, K. Cariou, R. H. Dodd, Eur. J. Org Chem. 2014, 2942-2955; c) F. Beaumard, P. Dauban, R. H. Dodd Synthesis 2010, 4033-4042.

[20] D. S. Hewings, O. Fedorov, P. Filippakopoulos, S. Martin, S. Picaud, A. Tumber, C. Wells, M. M. Olcina, K. Freeman, A. Gill, A. J. Ritchie, D. W. Sheppard, A. J. Russell, E. M. Hammond, S. Knapp, P. E. Brennan, S. J. Conway, J. Med. Chem. 2013, 56, 3217-3227. 


\section{Entry for the Table of Contents}

\section{COMMUNICATION}

$$
\begin{aligned}
& \mathrm{R}^{1}-\mathrm{BP} \text { in } \quad \mathrm{R}^{2}-\mathrm{BMIDA} \\
& \underset{\mathrm{Cl}}{\stackrel{\mathrm{Br}}{\mathrm{Kd}(\mathrm{OAc})_{2}, \text { DavePhos }}} \underset{\mathrm{K}_{3} \mathrm{PO}_{4}, \mathrm{H}_{2} \mathrm{O}, \mathrm{THF}, 90^{\circ} \mathrm{C}}{\mathrm{R}^{2}} \\
& \begin{array}{l:l}
1^{\text {st }} \text { coupling } & \cdot 2 \times \text { chemoselective oxidative addition } \\
2^{\text {nd }} \text { coupling } & -2 \times \text { chemoselective transmetallation } \\
\hline & \text { chemoselective speciation control }
\end{array} \\
& \text { one-pot } \\
& \text { aryl, heteroaryl, alkenyl, alkyl }
\end{aligned}
$$

Chemoselective Suzuki-Miyaura cross-coupling has previously been limited to single $\mathrm{C}-\mathrm{C}$ bond formation due to a lack of nucleophile selectivity. Manipulation of boron speciation enables complete chemoselective control of the Suzuki-Miyaura reaction, allowing harmonized sequential cross-coupling in a single operation.
Ciaran. P. Seath, James W. B. Fyfe, John J. Molloy and Allan J. B. Watson*

Page No. - Page No.

Tandem one-pot chemoselective Suzuki-Miyaura cross-coupling enabled by nucleophile speciation control 